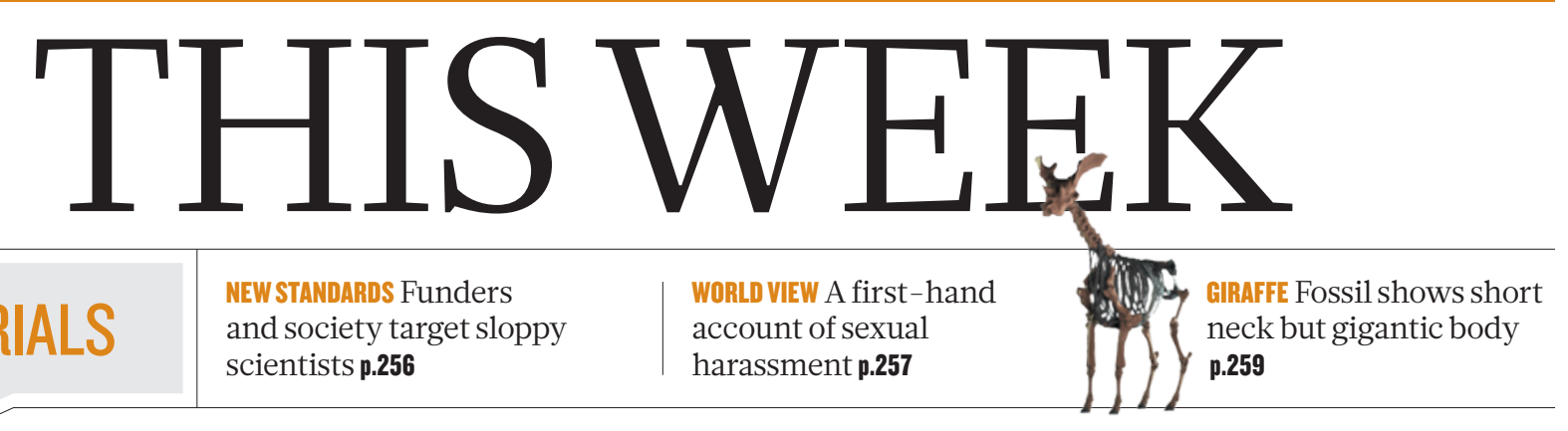

\title{
Harassment victims deserve better
}

\author{
Sexual harassment is rife in science. Universities must stop trying to save face: they must discipline \\ perpetrators and support victims.
}

$\mathrm{H}$ ow many senior scientists - usually men and usually with significant power over the careers of those in their labs have been sanctioned and disciplined by their universities for sexual harassment? Nobody knows, especially not young researchers who eagerly apply for their first jobs, spend long hours on fieldwork and feel under pressure to socialize and make contacts after hours and at academic conferences. How many times have colleagues turned a blind eye to inappropriate comments and actions, and made excuses for people who should know better - and who are morally, legally and contractually obliged to behave better? How many young scientists have left positions, or left science completely, because of such behaviour, or because it is seemingly not taken seriously?

We don't know the answers to those questions. But one thing we do know is that sexual harassment is a serious problem in science. And we know that young female scientists are speaking up about it. We know this not because universities are being transparent about such complaints and how they are dealt with, but because, dissatisfied with the official responses, victims, journalists and others are bringing the facts about these complaints to light.

On page 257 of this issue, for example, Nature publishes the testimony of a female researcher who was persistently harassed by a senior male colleague. His university investigated and upheld her complaint. But it told her to keep the matter confidential, and although it promised action against him, allowed the offender to stay in his post. Nature knows who he is, but in this case, the female researcher did not want to name him for fear of reprisals.

Apologists for sexual harassment will tell you that it 'is rarely a black and white issue' and that inappropriate behaviour often 'falls into a grey area'. Read this woman's story: having an influential male colleague 30 years your senior ask to stay at your house for a work trip, request kisses and then enquire whether his night-time masturbation kept you awake is $100 \%$ wrong.

Nature and others have encouraged scientists to stand up to such behaviour. But it is clear that the system is weighted towards protecting powerful faculty members at the expense of students and young researchers. Although institutions proclaim that they have zero tolerance for abuse of the policies that they claim to enforce, too often their primary concern seems to be secrecy and reputation management.

A string of cases in the US astronomy community demonstrates this. In each, a university investigated sexual-harassment claims against a faculty member, found the claims substantiated and attempted to bury that fact from public view.

The latest disclosures, made public last week, revealed that astrophysicist Christian Ott of the California Institute of Technology (Caltech) in Pasadena was suspended without pay last year for harassing two female graduate students. And Congresswoman Jackie Speier (Democrat, California) took the extraordinary step of decrying sexual harassment in science on the floor of the US House of Representatives.

She entered into the Congressional Record a 2005 University of Arizona finding of harassment regarding Timothy Slater, an astronomy educator who later moved to the University of Wyoming in Laramie.

These incidents follow probably the most high-profile recent case, which saw exoplanet hunter Geoffrey Marcy leave the University of California, Berkeley, late last year, but only after complaints and a university finding against him were revealed by news media.

\section{"Any principal investigator who thinks, 'It cannot happen at $m y$ university,' is wrong."}

There have been baby steps in the right direction, such as the effort by US President Barack Obama's administration to make it clearer to students what their rights are and how they can go about reporting a sexual violation. And Speier is working to force the US Department of Education to make sure that when a person found to have violated the law changes institutions, all institutions involved are aware of the situation.

Any principal investigator who thinks, "It cannot happen at my university," is wrong. These are not one-off cases. They are examples of a systemic underlying rot that is driving many young researchers out of science for good.

\section{Blue future}

\section{Coastal wetlands can have a crucial role in the fight against climate change.}

$\mathrm{O}$ ver the past decade, scientists and policymakers have joined efforts to create a science-based framework under the auspices of the United Nations to protect our remaining tropical forests. These carbon-rich ecosystems help to moderate the climate and serve as a treasure trove of biodiversity and a resource for local and indigenous peoples. Governments across the tropics have begun to incorporate forest conservation into their climate and development plans. Now it is time to do the same with coastal wetlands.

Some $2.4-4.6 \%$ of the world's carbon emissions are captured and sequestered by living organisms in the oceans, and the UN estimates that at least half of that sequestration takes place in 'blue-carbon' wetlands. Often occupied by seagrass and mangroves, these saltwater ecosystems promote healthy fisheries and sequester carbon in their soils. Mangroves 
also stave off erosion and serve as the first line of defence against powerful storms as well as saltwater intrusion into local groundwater resources. The world has lost more than one-third of its mangroves over the past several decades, and more succumb each year to shrimp farms, rice paddies and palm plantations, as well as to tourism and realestate development. There's money to be made, but it's the environment that pays.

Nascent efforts are under way to halt this degradation, and a few pioneering projects have already shown success. Senegal is home to the world's largest mangrove restoration project, which began in 2008. Villagers have planted around 79 million mangrove trees across more than 7,900 hectares. The project has been registered and certified under the Kyoto Protocol's Clean Development Mechanism (CDM), and is benefiting from the sale of carbon credits.

In 2010, the United Nations Environment Programme launched the Blue Carbon Initiative, which seeks to reverse current trends and increase the area of coastal wetlands under effective management by 2025 . The global climate agreement signed in Paris last December opens the door to advance such efforts, for example by enabling carbon trading and a programme similar to the CDM that allows countries and companies to pay to reduce emissions or build carbon stocks in projects such as the one in Senegal. It will be up to governments to incorporate coastal management into their climate plans, and to begin creating what some have called the 'blue-green economy'.

The available evidence justifies the pursuit of these efforts. Mangrove ecosystems alone could store as much as 20 billion tonnes of carbon - equivalent to more than 2 years of global carbon emissions - in their soils, much of which would be released into the atmosphere if the trees were destroyed. A 2012 study suggested that mangrove conservation could be effective at a cost of just US\$4-10 per tonne of carbon dioxide, which is within the current range of prices on the

European carbon trading system (J. Siikamäki et al. Proc. Natl Acad. Sci. USA 109, 14369-14374; 2012).

In some cases, mangrove protection and restoration could even benefit from the existing forest-carbon-trading framework, which enables developed countries to invest in efforts to reduce deforestation in the developing world. But more science is needed, both to document the extent and causes of the problem and to provide the data that will be

"The planet that humanity calls home already knows how to sequester carbon." needed if countries are to incorporate coastal wetlands into their carbon inventories and climate planning. We know too little about what happens to the carbon locked up in plants and soils when they are converted for other uses.

Just as occurred with remedying tropical deforestation, science and policy can move forward in parallel. As countries establish coastal management policies, they will help to drive the development of both science and policies. One opportunity is in the Dominican Republic, which has devised a comprehensive plan to reduce emissions by conserving and restoring mangrove forests. That project is registered with the UN, and it incorporates scientific objectives, including quantification of the carbon sequestration and storage capacity of these ecosystems. This will inform the policy framework and provide the scientific basis for any economic returns that the initiative may reap years and decades into the future.

Meeting the objectives of the Paris agreement - to contain global warming over the course of the twenty-first century - will require urgent action on all fronts. Countries must work to reduce industrial carbon emissions, but ensuring that natural ecosystems continue to function is equally vital - and relatively simple. The planet that humanity calls home already knows how to sequester carbon. Let's make our forests and coastal wetlands work for us.

\section{Repetitive flaws}

\section{Strict guidelines to improve the reproducibility of experiments are a welcome move.}

F rom next week, scientists who submit grant applications to the US National Institutes of Health (NIH) will be asked to take a little more care. As part of an increasing drive to boost the reliability of research, the NIH will require applicants to explain the scientific premise behind their proposals and defend the quality of their experimental designs. They must also account for biological variables (for example, by including both male and female mice in planned studies) and describe how they will authenticate experimental materials such as cell lines and antibodies.

These demands are timely, sensible and, if researchers have been following the advice of their scientific societies, will sound familiar. Over the past year, a string of organizations have published their own statements and guidelines to boost the reproducibility of research.

Collectively, the message is: show your work, and don't fool yourself with unreliable reagents or shoehorned data. Updated guidelines from the Federation of American Societies for Experimental Biology, for example, call for standard ways to cite antibodies and animal-care practices. The Society for Neuroscience has asked for random sampling of everything from subjects to cell parts whenever an entire population is not studied. The American Psychological Association has called for infrastructure and policies to promote data sharing. The Biophysical Society has detailed how to make experimental data widely accessible. And the American Society for Cell Biology has called for subdisciplines to create community standards for assays. More guidelines are in the works, and funders and journals have weighed in too.
These will help to create studies that are more sound. Other biomedical funders should follow the lead of the NIH and introduce similarly tangible requirements.

The NIH has stated that communication and awareness are crucial to address the lack of reproducibility in research. But unreliable work has many causes - and aspects of today's scientific landscape can thwart quality research. Competition for funding and faculty positions, and for the publications necessary to secure them, encourages uncritical acceptance of results. All too often, it is better to be first but wrong than scooped and right. Journals, including this one, have gone some way to acknowledge and take up their responsibility for this (see go.nature.com/huhbyr).

At the same time, experiments have become outsourced. Kits and reagents bought from commercial vendors allow scientists to do more research in a fraction of the time needed for 'home-brew' experiments with reagents created in the lab. These resources are invaluable but leave scientists less able to anticipate and identify artefacts.

Guidelines can cut down on mistakes from rushed publications and help to disseminate knowledge that would otherwise have to be gained by experience. But the real power of such recommendations lies less in their specific contents and more in the values that produced them.

Civil society depends on people acting according to societal norms, even when not doing so is unlikely to bring punishment. Citizens' motivation is not to gain material resources but to maintain their integrity. Similarly, the scientific community depends on researchers who adhere to values that are embodied in guidelines and recommendations. Doing quality research offers intrinsic rewards.

Guidelines work best when they build a culture that makes proper behaviour second nature. They can help to make $\rightarrow$ NATURE.COM To comment online, click on Editorials at: go.nature.com/xhunqv researchers aspire to the values that produced them. They are valuable not only because scientists follow them but also because they can inspire researchers to uphold their identity and integrity. 


\section{CORRECTION}

The Editorial 'Blue future' (Nature 529,

255-256; 2016) should have said that $2.4-4.6 \%$ of the world's carbon emissions are captured and sequestered by living organisms in the oceans. 